\title{
LAS CLAÚSULAS DE MEDIACIÓN EN EL NEGOCIO INMOBILIARIO
}

\author{
THE MEDIATION CLAUSES IN THE REAL ETATE BUSINESS
}

\author{
MARIA PILAR MORGADO FREIGE \\ Universidad de Alcalá
}

\begin{abstract}
Resumen: La mediación supone un instrumento ágil, eficaz y poco costoso de resolver conflictos en el orden civil y mercantil alternativo a la resolución judicial. La introducción de cláusulas en los contratos inmobiliarios que faciliten la misma en materias relativas a la vivienda, arrendamientos urbanos, préstamos hipotecarios y propiedad horizontal supone un avance en orden a la resolución de conflictos planteados en estas materias de forma extrajudicial.
\end{abstract}

Palabras clave: mediación, contrato inmobiliario, arrendamientos urbanos, propiedad horizontal.

Abstract: mediation is an agile, effective and inexpensive instrument to resolve conflicts in the civil and commercial order that is alternative to the judicial resolution. The introduction of clauses in real estate contracts that facilitate the same in matters relating to housing, urban leases, mortgage loans and horizontal property is an advance in order to resolve conflicts raised in these matters extrajudicially.

Keywords: mediation, real estate contract, urban leases, horizontal property.

SUMARIO: 1. CONCEPTO Y JUSTIFICACIÓN. 2. LA MEDIACIÓN EN LA CONTRATACIÓN INMOBILIARIA: 2.1. En materia de vivienda. 2.2. En materia de arrendamientos. 2.3. En el ámbito hipotecario. 3. LA MEDIACIÓN EN LA PROPIEDAD HORIZONTAL.

\section{CONCEPTO Y JUSTIFICACIÓN}

Junto con el arbitraje, la mediación constituye otro de los sistemas alternativos de resolución de los conflictos que tiene en la actualidad un indudable protagonismo, y que resulta de especial interés en el sector inmobiliario, siendo citada en distintos foros la potenciación de la mediación y el arbitraje como una de las cuestiones clave frente al colapso judicial, al mismo tiempo que la simplificación de procedimientos y otras medidas, en aras a modernizar la justicia y, con ello, contribuir al desarrollo económico y al bienestar ${ }^{1}$.

La mediación va a contribuir, como lo ha hecho en los países de tradición de common-law, a la mejora de la calidad de la justicia, puesto que es una herramienta de eficacia contrastada a disposición de los operadores jurídicos, fundamentalmente

1 PÉREZ MIRALLES, J.A.: Arbitraje y mediación inmobiliaria. Especial referencia a la propiedad horizontal, Ed. Tirant lo Blanch, Valencia, 2012, p. 40. 
de la abogacía, para resolver litigios de forma consensuada en aquellos casos en los que la negociación haya fracasado, y es un recurso a disposición de los tribunales para que en determinados conflictos en los que las partes deben seguir manteniendo relaciones en el futuro, la actuación de la justicia no se limite a imponer dinámicas de vencedores y vencidos, sino que ofrezca una oportunidad a los ciudadanos para que transformen sus disputas en relaciones viables de colaboración ${ }^{2}$.

Son muchas las definiciones que se han dado sobre la mediación, pero cabe destacar la proporcionada por AVILÉS NAVARRO contenida en el Libro Blanco sobre Mecanismos Extrajudiciales de Solución de Conflictos en España, donde la mediación figura «como un procedimiento voluntario, informal y confidencial, por el que una tercera persona neutral, con una formación adaptada a las necesidades del conflicto, asiste a las partes con el objeto de que éstas lleguen a un acuerdo por sí mismas» ${ }^{3}$.

El protagonismo global de las soluciones alternativas a la vía judicial derivado de la internacionalización en la contratación y consiguiente superación de fronteras se ha adjudicado a las ADR (Alternative Dispute Resolutions). Entiéndase por ADR aquellos procedimientos que conducen a la solución del conflicto mediante la intervención de un tercero que propone o impone la solución y que se presentan como modalidad de resolución de conflictos basadas más en el consenso hacia el que se trata de guiar a las partes que en la resolución que impone un juez o un árbitro ${ }^{4}$. En opinión de ROGEL VIDÉ se trata de alternativas al proceso -al arbitraje incluso-, a pesar de que, en tales casos y a la postre, lo que resuelve la disputa es la sentencia - 0 el laudo-, siendo el proceso -o el arbitraje-, cual la mediación -que desemboque en la transacción-, meros cauces o medios para lograr el resultado apetecido, por mucho que en ocasiones se confunda el camino seguido con la meta perseguida ${ }^{5}$

La promulgación de la Ley 5/2012, de 6 de julio, de mediación en asuntos civiles y mercantiles significó la posibilidad de regular la mediación como solución práctica, fácil y más económica para resolver cuestiones en el ámbito contractual de forma extrajudicial evitando de esta forma una excesiva judicialización a la hora de interpretar y ejecutar las cláusulas contractuales.

El art. 2 de la citada Ley 5/2012, de 6 de julio, de mediación en asuntos civiles y mercantiles, al hacer referencia al ámbito de aplicación de la ley señala que "1. Esta Ley es de aplicación a las mediaciones en asuntos civiles o mercantiles, incluidos los conflictos transfronterizos, siempre que no afecten a derechos y obligaciones que no estén a disposición de las partes en virtud de la legislación aplicable.

ORTUÑO MUÑOZ, P.: “A propósito del ámbito de la directiva 2008/52/ce, sobre medición, en asuntos civiles y mercantiles". Rev. Doctrinal Aranzadi Civil-Mercantil, nº 20/2008, Ed. Aranzadi, Cizur Menor, 2008, p. 1.

3 "La mediación en los diferentes órdenes jurisdiccionales", Diario LA LEY, año XXXII, $\mathrm{n}^{\mathrm{0}} 7704,28$ de septiembre 2011.

4 PÉREZ MIRALLES, J.A.: Arbitraje y mediación ..., p. 41.

5 "Mediación y transacción en el Derecho Civil" en Mediación, arbitraje y resolución extrajudicial en el siglo XXI, GARCÍA VILLALUENGA, L., TOMILLÓN URBINA, J. L. y VÁZQUEZ DE CASTRO, E. (Codirectores), Ed. REUS, Madrid, 2010, p. 1. 
En defecto de sometimiento expreso o tácito a esta Ley, la misma será aplicable cuando, al menos, una de las partes tenga su domicilio en España y la mediación se realice en territorio español.

2. Quedan excluidos, en todo caso, del ámbito de aplicación de esta Ley:

a) La mediación penal.

b) La mediación con las Administraciones públicas.

c) La mediación laboral.

d) La mediación en materia de consumo".

A diferencia de ella, el art. 2 de la Ley catalana 15/2009, de 22 de julio ${ }^{6}$ efectúa una amplia enumeración a modo de ejemplo de una serie de ámbitos del Derecho privado que comprende la mediación, distinguiendo los supuestos de mediación familiar, incluida la mediación en el ámbito del Derecho de sucesiones y los de mediación civil, la cual comprende cualquier tipo de cuestión o pretensión en materia de Derecho privado que pueda conocerse en un proceso judicial y que se caracterice porque se haya roto la comunicación personal entre las partes, si éstas deben mantener las relaciones en el futuro", señalando particularmente los conflictos en el ámbito de asociaciones y fundaciones, de la propiedad horizontal y urbanizaciones, de la convivencia ciudadana o social y los interculturales, para concluir con una cláusula cierre que la dota de mayor amplitud, al incluir "cualquier otro conflicto de carácter privado en que las partes deban mantener relaciones personales en el futuro, si razonablemente, aún pueden evitarse la iniciación de un litigio ante los juzgados o puede favorecerse la transacción", debiéndose indicar que aunque el texto del precepto se refiera a "conflictos relacionales", no excluye que la cuestión de fondo sea económica $^{7}$.

Una vez fijado el ámbito de la mediación, sus límites y las materias excluidas y ante la ausencia de una previsión expresa por parte de la Ley 5/2012, cabe señalar que existe un amplio abanico de materias que son susceptibles de ser objeto de

6 Ley aprobada por el Pleno del Parlamento Catalán en la Sesión $n^{0}$ 60, del 15 de julio de 2009 (DSPD-P 89). Dicha Ley deroga la Ley catalana de mediación familiar 1/2001, de 15 de marzo. En el Preámbulo de la Ley catalana de 2009 se dice que la misma se inscribe en una corriente europea para la actualización de las leyes de mediación indicándose también que Austria -Ley 29/2003-y Bélgica-Ley de 21 de febrero de 2005- han promulgado leyes generales de mediación, no circunscritas al ámbito familiar y válidas para la mediación comunitaria, social, ciudadana, para los conflictos derivados de compartir un espacio común, las relaciones de vecindad, profesionales, asociativas, colegiales, empresariales o las que puedan suscitarse en asuntos civiles y mercantiles. Vid. ROGEL VIDÉ, Op. ya cit., p.7.

En opinión de POSE VIDAL, S. "Comentario al artículo 2" en Comentarios a la Ley catalana 15/2009, de 22 de julio, de mediación en el ámbito del Derecho privado y concordantes, VIOLA DEMESTRE, I. (Dir.), Ed. Marcial Pons, Madrid, 2018, p. 30, tal configuración pone de manifiesto que la mediación civil se considera aconsejable, y prioritaria a la vía judicial, en aquellos casos en los que las partes se enfrentan a una relación duradera en el tiempo, respecto de la cual la solución del conflicto mediante acuerdo, en lugar de decisión judicial, puede contribuir de manera mucho más eficaz a la pacificación de la relación y al restablecimiento del diálogo entre las partes 
mediación civil. Entre ellas cabe citar la mediación inmobiliaria, con un prolífico ámbito de aplicación en materia de compraventa, contratos de ejecución hipotecaria y arrendamientos urbanos, así como propiedad horizontal.

\section{LA MEDIACIÓN EN LA CONTRATACIÓN INMOBILIARIA}

La mediación inmobiliaria tendrá por objeto todas las controversias relacionadas con el sector inmobiliario que hayan surgido o puedan surgir de las relaciones jurídicas que tienen por objeto los inmuebles. Tanto en el sentido amplio a que se refiere el Código Civil, en su art. 334, como en su acepción registral, como finca. La duda que puede plantearse es si sólo en los relativo al inmueble ${ }^{8}$ o si se puede ampliar a todas aquellas controversias que se deriven de un contrato que tenga por objeto un inmueble, como es el caso del arrendamiento, por ejemplo.

El sometimiento a una mediación o a un arbitraje inmobiliario no ha de implicar necesariamente que la cuestión controvertida tenga relación directa con el inmueble, sino que bastará con que se encuentre en la órbita del inmueble que surja como consecuencia complementaria, o a colación, de una relación jurídica base de carácter inmobiliario en el que las partes hayan convenido la sumisión a arbitraje, y en la que el inmueble sea el núcleo u objeto principal de la relación. La mediación inmobiliaria no es sino una mediación especial más con semejanzas con el resto de arbitrajes sectoriales, pero con ciertas singularidades ${ }^{9}$.

Como ya hemos citado, una de las materias que merecerían ser objeto de mediación es la compraventa inmobiliaria ${ }^{10} \mathrm{y}$ el préstamo hipotecario.

8 Por ejemplo el art. 52 del Anteproyecto de Ley de la Vivienda de Aragón se centra en la vivienda como objeto de la mediación: "Artículo 52. Fomento de los sistemas extrajudiciales de resolución de conflictos.

1. Las administraciones públicas de Aragón fomentarán la creación y utilización de sistemas de resolución extrajudicial de los conflictos que puedan surgir entre los distintos agentes que operen en relación con la vivienda, especialmente cuando esté afectado el derecho a la vivienda.

2. Los sistemas de resolución extrajudicial de conflictos en materia de vivienda incluirán la mediación y cualesquiera otros que vayan destinados a la misma finalidad, incluidos los previstos en la normativa en materia de protección de consumidores, según las determinaciones previstas en este capítulo.

3. Las partes en conflicto deberán acudir necesariamente a un sistema de mediación, de acuerdo con lo previsto en este capítulo, sin perjuicio de que, posteriormente a la finalización sin acuerdo de este procedimiento, puedan sujetarse a un sistema de arbitraje". Vid www.aragonparticipa.aragon.es

9 PÉREZ MIRALLES, J.A.: Arbitraje y mediación ..., pp. 69 y70.

10 Si bien argumenta en contrario CREMADES B. M. en "El Convenio arbitral", Diario La Ley $\mathrm{n}^{\circ} 5754,4$ de abril de 2003, Madrid, pág. 6, que ya existe un procedimiento arbitral regulado en la Ley de Arbitraje y que no es necesario nuevos procedimientos específicos, ya que dicha técnica legislativa va en detrimento de la seguridad jurídica y debe evitarse su sucesivo replanteamiento legislativo, pero también es cierto que el fundamento social que sustentaría el tratamiento especial de la vivienda en sede arbitral, y en especial la gratuidad o la posible resolución en equidad goza de la suficiente relevancia para justificar el diferente y especial tratamiento. 


\subsection{En materia de vivienda}

Con carácter general, la mediación en el ámbito inmobiliario, puede centrarse en el contrato de compraventa, cuya regulación específica en el Código Civil (artículos 1445 a 1506) posee mayoritariamente carácter dispositivo, por lo que no existen límites a la actividad mediadora en este ámbito, con excepción de la prohibiciones de contratar recogidas en el art. 1459 CC. La figura de la mediación puede encontrar aplicación en el momento de la celebración del contrato, a la hora de determinar su objeto, sobre todo en supuestos de compraventa de vivienda en construcción. Igualmente puede ser útil la mediación para la fijación del precio, ya que el propio art. 1447 CC admite expresamente que su señalamiento o determinación se deje al arbitrio de un tercero, por lo que evidentemente podría ser objeto de mediación entre las partes, y teniendo siempre en cuenta que el art. 1449 CC prohíbe que tal cuestión quede en manos de uno de los contratantes.

Ahora bien, centrándonos en la vivienda aun cuando podría excluirse el arbitraje o la mediación en aquellas cuestiones relativas a la vivienda familiar por referirse a supuestos patrimoniales dentro de los contenciosos matrimoniales, en nuestra opinión, no puede quedar ajena a la medición inmobiliaria todas aquellas controversias que se derivan del contrato de compraventa de inmuebles entre los particulares. Si bien, se alega que para este tema ya está regulado el arbitraje de consumo, puede contestarse que el arbitraje de consumo no excluye al arbitraje inmobiliario. El arbitraje de consumo se establece partiendo de las desiguales posiciones entre vendedor-promotor y comprador-cliente, pero no todo arbitraje inmobiliario es arbitraje de consumo, por lo que sería conveniente y merecería la importancia del sector que se estableciera de "lege ferenda", un arbitraje institucional y privilegiado en materia de vivienda.

Arbitraje que no debe ser otro que un arbitraje específicamente inmobiliario donde la protección se dispense por razón del objeto, y la función que cumple, lo que le diferenciaría claramente del arbitraje de consumo cuya tutela se dispensa en atención a los sujetos de la relación. Es decir, la vivienda no debería de recibir la tutela vía arbitraje de consumo, o al menos no es el arbitraje más apropiado, sino que tal protección debería dispensarse a través de un específico arbitraje inmobiliario en la medida en que dicha tutela descansaría, no tanto en los sujetos de la relación, esto es, en la situación o no de inferioridad o desequilibrio de una de las partes, el consumidor final, respecto a la contraria, y que constituye el fundamento del derecho de consumo y de su arbitraje sectorial, como en la esencia o destino del objeto de la relación jurídica, con independencia de quienes la integren y de cuál sea su posición, esto es, la vivienda como inmueble destinado a satisfacer una necesidad primaria de la persona o de cualquier otra con un interés económico diferente ${ }^{11}$.

\subsection{En materia de arrendamientos}

Una de las materias en las que es factible la mediación es en el ámbito del contrato de arrendamiento, especialmente en los arrendamientos urbanos. En la LAU de

11 PÉREZ MIRALLES, J.A.: Arbitraje y mediación ..., p.159. 
1994 y en base a su art. $39.5^{12}$ se mostraba el arbitraje como una alternativa a la vía jurisdiccional para la resolución de conflictos derivados del contrato, pero la LEC $1 / 2000$ al derogar ${ }^{13}$ los artículos 38 a 40 de la LAU relativos a los procesos arrendaticios se abrió al arbitraje como alternativa en el marco de la Ley de Arbitraje de 2003. Criterio mantenido por la LAU tras su reforma por Ley 4/2013, de 4 de junio en cuyo art. 4.5 se insistía en "Las partes podrán pactar la sumisión a mediación o arbitraje de aquéllas controversias que por su naturaleza puedan resolverse a través de estas formas de resolución de conflictos, de conformidad con lo establecido en la legislación reguladora de la mediación en asuntos civiles y mercantiles y del arbitraje”.

No obstante, hoy por hoy la concreción práctica del arbitraje en materia de arrendamientos plantea no pocas dificultades. Por una parte, porque ni la LAU, ni la Ley de Arbitraje aclaran que tipo de arbitraje debe ser aplicado, tal y como se puede apreciar en los Autos de la Audiencia Provincial de Madrid de 13 de septiembre de $2007^{14}, 22$ de enero de $2008^{15}$ y 22 de enero de $2009^{16}$. La cuestión que se plantea es si ese arbitraje debe ser en equidad o un arbitraje en Derecho. En opinión de MORE$\mathrm{NO}$, a pesar que pudiera haber cuestiones que se podrían resolver en equidad, atendiendo a las normas imperativas ${ }^{17}$, entiende que el arbitraje idóneo para esta materia es el arbitraje en Derecho y además para obviar cualquier duda sobre la consideración de consumidor o no del arrendatario, debería ser un arbitraje Institucional ${ }^{18}$.

Por otra, porque su ámbito de aplicación, según prescribe la mencionada Ley $60 / 2003$, se circunscribe a aquellas materias que sean de libre disposición para las partes conforme a derecho.

Comoquiera que la Ley no especifica cuáles son esas materias de libre disposición, nos hallamos frente a un concepto jurídico indeterminado, con la consiguiente inseguridad jurídica que para las partes puede conllevar su concreción, interpretación y aplicación en cada caso concreto ${ }^{19}$.

No obstante, nos encontramos en esta materia dentro del ámbito del Derecho contractual, de libre disposición por las partes con aplicación del principio de autonomía de la voluntad, por lo que el campo de la acción de mediación, es en principio,

12 Establecía que "las partes podrán pactar el sometimiento de los litigios a los tribunales arbitrales, de conformidad con lo establecido en la Ley 36/1988, de 5 de diciembre”.

13 2. Quedan también derogados los siguientes preceptos, leyes y disposiciones: $6 .^{\circ}$ Los artículos 38 a 40, incluido, de la Ley 29/1994, de 24 de noviembre, de Arrendamientos Urbanos.

14 JUR 2007/325832.

15 JUR 2008/98671.

16 JUR 2009/157780.

17 Cabe citar en este sentido, la STS de 21 de marzo de 1985 (RJ 1985/1193).

18 "El arbitraje arrendaticio con especial referencia al arbitraje del Consejo arbitral para el alquiler de la Comunidad de Madrid" en Arbitraje y mediación en el ámbito arrendaticio MARÍA PÉREZ-UGENA (Coord.), Ed. Dykinson, Madrid, 2017, pp.158 y 159.

19 Para CORTÉS, J. M. "Arbitraje en materia de arrendamientos". Actualidad Jurídica, Ed. Aranzadi, año XVIII, no 748, 27 de marzo de 2008, p.2 supone que pese a la lentitud en la resolución de los pleitos arrendaticios, especialmente grave en algunas ciudades, sigue siendo preferible acudir a los órganos judiciales para resolver las controversias en materia arrendaticia. 
el más amplio posible. Ello no obsta, el hecho de que el art. 6 LAU, norma especial en materia de renuncia de derechos, prohíba la renuncia de derechos concedidos al arrendatario de vivienda por el Título II salvo cuando la Ley expresamente lo permita, ya que esta limitación parcial a la facultad de renuncia ha sido interpretada reiteradamente por la jurisprudencia en el sentido de entender que únicamente es nula la renuncia anticipada en el contrato, pero que es plenamente admisible la renuncia una vez que los derechos concedidos por la Ley están en su patrimonio.

Las cuestiones que en mayor medida pueden dar lugar a la mediación entre las partes en este ámbito son las relativas a:

- La determinación de las obligaciones del arrendatario, como a la hora de fijación de la renta (art. 17.1 LAU), de su actualización (art. 18 LAU), de los gastos generales (comunidad de propietarios, tributos) o individuales (agua, electricidad, gas) que asume el arrendatario (art. $20 \mathrm{LAU}$ ) o de precisar las obras de reforma o rehabilitación que haya de ejecutar en la finca en caso de que se sustituya por ella la obligación de pago de la renta (art. 17.5 LAU).

- La determinación e incumplimiento de las obligaciones del arrendador, principalmente la extensión que ha de darse a la obligación de conservación de la finca en condiciones de habitabilidad para servir a su uso (artículos $1554.2^{\circ}$ CC y 21.1 y $30 \mathrm{LAU})$, será igualmente otro campo habitual de disputas entre las partes para el que presenta enorme utilidad la intervención de un mediador.

- La determinación de las obras de mejoras permitidas al arrendatario o de las obras necesarias para la adecuada accesibilidad de la finca conforme a los artículos 23 y 24 LAU y la Ley 15/1995, y en su caso la fijación de la indemnización al arrendatario que las realice cuando queden en beneficio de la propiedad (si así se pactó, artículos 487 y 1573 CC).

\subsection{En el ámbito hipotecario}

Además de la mediación en la Propiedad Horizontal, a la que nos referiremos posteriormente, hay que tratar la mediación en el ámbito hipotecario.

El sector de los préstamos hipotecarios se presenta como otro de los ámbitos en los que el instrumento de la mediación presenta gran interés para la resolución de los conflictos que surjan entre las partes, especialmente en la actual situación de crisis económica y paro para numerosas familias españolas que les impide hacer frente al pago inmediato de las deudas contraídas con la entidad prestamista ${ }^{20}$.

20 Para ADÁN DOMENECH, las dudas sobre la proporcionalidad de las obligaciones de las partes contractuales de las obligaciones de las partes contractuales ha condicionado la posterior actividad legislativa en materia hipotecaria en los últimos años. La comparación entre la Exposición de Motivos de la Ley 1/2000, de 7 de enero, de Enjuiciamiento Civil y el Preámbulo de la Ley $1 / 2013$, de 14 de mayo de medidas para reforzar la protección a los deudores hipotecarios, restructuración de deuda y alquiler social, constituye un ejemplo claro de un cambio de filosofía en la reglamentación hipotecaria, en "La mediación en la ejecución hipotecaria", Revista Vasca de Derecho Procesal y Arbitraje, 2016 (1), p. 36. 
Es en estos supuestos de imposibilidad de cumplimiento normal de la obligación de pago en los que aparece como deseable la intervención del mediador (no parece lógica la intervención en supuestos de normalidad) ${ }^{21}$, quien podría reunir a entidad bancaria y a deudor para buscar fórmulas ágiles de solución del conflicto $^{22}$.

Se entiende por mediación hipotecaria, aquel proceso autocompositivo de resolución de controversias en el que con la intervención de un tercero, el deudor y acreedor hipotecarios, como consumidor y empresario respectivamente, intentan alcanzar voluntariamente un acuerdo de reestructuración del préstamo que permitan al primero continuar con el pago de la hipoteca, o bien paliar su estado de sobreendeudamiento intentando siempre preservar la vivienda ${ }^{23}$.

El arbitraje hipotecario, teniendo en cuenta el posible carácter abusivo del pacto de sometimiento a arbitraje o la fuerza atractiva del arbitraje de consumo ${ }^{24}$ cuando intervenga un consumidor, puede parecer muy limitado en su aplicación práctica. Sin embargo, sí que existen diversos escenarios en que es posible y conveniente la resolución de controversias derivadas de los contratos de préstamo hipotecario mediante el arbitraje evitando de esta forma recurrir a la justicia ordinaria.

${ }^{21}$ Así, diferentes Colegios de Abogados han creado en su seno unas denominadas "Oficinas de intermediación hipotecaria" que ofrecen, de manera totalmente gratuita, un servicio de información, asesoramiento y soporte a las personas que tienen dificultades para hacer frente a los pagos de los préstamos hipotecarios y están en riesgo de perder su vivienda habitual, facilitando la comunicación entre la parte deudora y la entidad financiera para encontrar una solución antes de una demanda de ejecución hipotecaria o durante el proceso de ésta (http://www.abogacia. es/2012/06/21/oficina-de-intermediacion-hipotecaria). Igualmente, algunas instituciones oficiales han creado servicios análogos, como el Departamento de Justicia del Gobierno Vasco (http:// www.justizia.net/mediacion-hipotecaria) o el Ayuntamiento de Pamplona (http://www.pamplona. es).

22 Para BASTANTE GRANELL en "Mediación Hipotecaria: Una solución al problema del sobreendeudamiento de los particulares", ANALES DEL DERECHO, n 31, 2013, p.185, es lógico que las entidades bancarias no se acojan a un sistema arbitral para solucionar el problema de sobreendeudamiento hipotecario. Generalmente, dicho problema es solucionado mediante negociaciones con la parte deudora, sin intervención de tercero. Los bancos no tienen interés en someterse a un procedimiento cuya resolución es vinculante y tampoco en permitir que sea un árbitro en el que establezca y decida la reestructuración hipotecaria.

23 BASTANTE GRANELL, "Mediación Hipotecaria: Una solución..., p. 186.

24 De hecho en el Proyecto de Ley reguladora de los contratos de crédito inmobiliario, en fase de tramitación en el Congreso de los Diputados se prevé en la Disposición Adicional Primera que "El prestamista inmobiliario o el intermediario de crédito inmobiliario y el prestatario consumidor podrán someter sus conflictos al arbitraje de consumo, de mutuo acuerdo o mediante adhesión de aquéllos al Sistema Arbitral del Consumo o a otros sistemas de resolución extrajudicial de conflictos, que figuren en la lista que publica la Comisión Europea sobre sistemas alternativos de resolución de conflictos con consumidores y que respete los principios establecidos por la normativa europea. Los prestatarios podrán también someter unilateralmente los conflictos a los mecanismos previstos en la legislación sobre protección de los clientes de servicios financieros". 
A modo de ejemplo podríamos citar ${ }^{25}$ :

a) Préstamos entre particulares que no estén sometidos a la Ley 2/2009 por la que se regula la contratación con los consumidores de préstamos o créditos hipotecarios y de servicios de intermediación para la celebración de contratos de préstamo o crédito $^{26}$.

b) Aquellos préstamos concedidos en situaciones de especial necesidad de financiación del prestatario y en que se negocien por las partes las clausulas concretas, entre las que podría encontrarse la de sumisión a arbitraje.

c) Los llamados préstamos preconcursales, teniendo en cuenta que, en la reforma por la Ley 11/2011 de la Ley Concursal se prevé la posibilidad de que declarado el concurso continúe subsistente la vigencia del convenio arbitral, salvo que el juez del concurso considere que es perjudicial para los intereses del mismo en resolución motivada.

d) Puede pactarse el sometimiento a arbitraje en cualquier contrato de préstamo hipotecario, cuando la cláusula se haya negociado individualmente por las partes y quede así reflejado claramente. Si se ha negociado individualmente, y se puede demostrar, escaparía a la concepción de cláusula abusiva.

e) Por último, no debemos olvidar que el arbitraje no necesariamente debe estar convenido en un momento anterior a la producción del conflicto, sino que una vez surgida la controversia las partes pueden llegar acordar someter la solución de la misma a arbitraje (art. 9.1 LA). En consecuencia, en supuestos de acuerdo expreso sería perfectamente válido dicho sometimiento y ello aunque se trate de un préstamo en que intervenga un consumidor.

Una vez planteada la posibilidad de someter a arbitraje o mediación a los préstamos hipotecarios, cabría estudiar qué cuestiones podrían ser objeto de las mismas. A título meramente enunciativo podría citar las siguientes ${ }^{27}$ :

a) Cuestiones relativas a la liquidación de la deuda y fórmulas aplicables para su determinación.

b) Procedencia y cálculo de comisiones.

c) Cuestiones relativas al vencimiento del préstamo y plazo. Períodos de carencia, ampliaciones, etc.

d) Controversias sobre la resolución y liquidaciones procedentes de coberturas pactadas de riesgo de interés, divisas y swaps.

e) Modificaciones de moneda y divisa e hipotecas multidivisa.

f) Determinación y cálculo del tipo de interés, índices de referencia y cálculo de intereses variables.

g) Condiciones para los casos de subrogaciones activas o pasivas en el préstamo.

25 REY BARBA, S: “¿Es posible el arbitraje hipotecario?, $R C D I, \mathrm{n}^{\mathrm{0}} 758,2016, \mathrm{p} .3182$.

26 En este sentido, cabe citar la RDGRN de 31 de mayo de 2016 ( $R J$ 2016/4003), sobre los requisitos que deben reunir los préstamos sometidos a esta ley.

27 REY BARBA, S: “¿Es posible el arbitraje... p. 3184. 
h) Cuestiones relativas a la tasación de los bienes hipotecados o pérdida de valor de los mismos con la necesidad de completar la garantía.

i) Cuestiones relativas a la interpretación y eficacia de las cláusulas de vencimiento anticipado.

No obstante todo lo expuesto anteriormente, la Ley 5/2012, de Mediación en asuntos civiles y mercantiles, que traspone la Directiva 2008/52/E, sobre ciertos aspectos de la mediación en asuntos civiles y mercantiles, no impone la obligación de acudir a mediación en ningún tipo de proceso y excluye expresamente su aplicación a los procesos de consumidores. Por otro lado, la Directiva, no establece el carácter necesario del intento de mediación pre procesal. El art. 5.2 de la misma prevé que "la presente Directiva no afectará a la legislación nacional que estipule la obligatoriedad de la mediación o que la someta a incentivo o sanciones, ya sea antes o después de la incoación del proceso judicial, siempre que tal legislación no impida a las partes el ejercicio de su derecho de acceso al sistema judicial". En esta línea cabe destacar que la Comunidad Autónoma de Andalucía instituye la mediación hipotecaria administrativa, es decir el tercero lo representa un órgano de la Administración, para casos de ejecuciones crediticias e hipotecarias sobre la vivienda a través del art. 17 de la Ley 3/2016, de 9 de junio, para la protección de derechos de las personas consumidoras y usuarias en la contratación de préstamos y créditos hipotecarios sobre la vivienda. Dicho precepto se enmarca en el Título III denominado Arbitraje, mediación y acciones de cesación y dispone en su apartado 3 que " $\mathrm{La}$ Administración de la Junta de Andalucía fomentará la mediación extraprocesal entre las empresas prestamistas y las personas consumidoras y usuarias, previa o simultáneamente con cualquier otro procedimiento de ejecución judicial o notarial, al objeto de alcanzar una solución consensuada, encaminada hacia la búsqueda de acuerdos que hagan viable que la persona consumidora y usuaria conserve la propiedad de la vivienda y, subsidiariamente, la posibilidad de mantener el uso de esta" ${ }^{28}$.

Todo ello a diferencia de lo previsto en el art. 132-4 del Código de Consumo de Cataluña ${ }^{29}$ donde el legislador catalán impone un procedimiento de mediación en el

${ }^{28}$ FERNÁNDEZ-FIGARES MORALES, M J.: "La mediación hipotecaria de Andalucía. Examen de la repercusión jurídico-procesal y la habilitación competencial de la Ley 3/2016 que la instaura", Actualidad Civil, nº 5, sección consumidores, mayo 2017, p.1.

29 "1. Las administraciones públicas catalanas y, especialmente, los servicios públicos de consumo deben garantizar que, en los casos de ejecución hipotecaria de la vivienda habitual como consecuencia del incumplimiento del deudor, pueda llevarse a cabo un procedimiento de mediación destinado a la resolución extrajudicial de conflictos previo a cualquier otro procedimiento judicial o a la intervención notarial.

2. El procedimiento de mediación debe tener por objeto buscar acuerdos entre las partes que hagan viable que la persona consumidora conserve la propiedad de la vivienda o, subsidiariamente, la posibilidad de mantener su uso y disfrute. En el marco de este procedimiento, las partes o el órgano de resolución extrajudicial de conflictos pueden solicitar un informe de evaluación social con un análisis socioeconómico del deudor y las posibles vías de resolución del conflicto en los términos del artículo 133-6.

3. Las partes en conflicto, antes de interponer cualquier reclamación administrativa o demanda judicial, deben acudir a la mediación o pueden acordar someterse al arbitraje. Una vez transcurrido el plazo de tres meses a contar de la notificación del acuerdo de inicio de la mediación 
ámbito de los procesos que tengan por objeto un préstamo hipotecario relacionado con la vivienda habitual.

Para PÉREZ DAUDí ${ }^{30}$, la obligatoriedad de acudir a la medición se aplica a todos los procesos relacionados con los créditos o préstamos hipotecarios. Es decir, se incluye la ejecución hipotecaria y los procesos relacionados con la declaración de nulidad del contrato de crédito o préstamo hipotecario o alguna de sus clausulas, como puede ser la de vencimiento anticipado o el suelo.

A la vista de lo anterior, entiendo que la mediación hipotecaria debe constituir una modalidad de mediación civil con singularidad propia, no como una especialidad del arbitraje de consumo y que tenga por objeto la reestructuración de los préstamos hipotecarios para evitar la ejecución o, al menos, el lanzamiento.

\section{LA MEDIACIÓN EN LA PROPIEDAD HORIZONTAL}

La mediación, además de reconocerse en el ámbito del derecho inmobiliario al que ya hemos hecho referencia, cobra un particular protagonismo en la Propiedad Horizontal y en particular a lo que se circunscribe a los conflictos derivados de la misma.

Si bien es cierto que el art. 24 de la Constitución española reconoce como derecho fundamental la tutela judicial efectiva, no es menos cierto que ésta reconoce la libertad individual como principio inspirador del arbitraje y la mediación. Ya en la propia Exposición de Motivos de la Ley de Propiedad Horizontal de 1960 se señalaba "que por obra de la voluntad se especifiquen, completen y hasta se modifiquen ciertos derecho y deberes", siempre que no se contravengan las normas de derecho necesario de la Ley, permitiendo de esta forma la posibilidad de introducir cláusulas de arbitraje en el Título constitutivo para solucionar diferentes problemas comunitarios $^{31}$. En este sentido, el Tribunal Supremo ha destacado en innumerables ocasiones el importante papel que asume el principio de autonomía de la voluntad en la configuración de la Propiedad Horizontal ${ }^{32}$. De hecho, poco a poco, en la práctica

sin haber alcanzado un acuerdo satisfactorio, cualquiera de las partes puede acudir a la reclamación administrativa o a la demanda judicial".

30 "Aspectos procesales de la mediación preceptiva en los procesos hipotecarios". Diario LA LEY, no 8541, Sección Tribuna, 18 de mayo de 2015. El autor concluye que el art. 132-4 del Código de consumo de Cataluña impone el carácter obligatorio de la mediación antes de interponer cualquier reclamación administrativa o demanda judicial relacionada con un crédito o préstamo hipotecario de la vivienda habitual. En el ámbito judicial, el demandante deberá aportar junto con la demanda el acta de inicio de la mediación y el acta final de la misma en la que se haga constar que no se ha llegado a un acuerdo. En el caso de no adjuntarla el Secretario Judicial deberá permitir que la parte actora subsane la falta de presentación permitiendo que se acuda la mediación y suspendiendo la admisión a trámite de la demanda. En el caso de no realizarlo en el plazo concedido se dará traslado al Tribunal para que inadmita la demanda.

31 Vid. STS de 28 de enero de 1994 ( $R J$ 1994/571), en referencia a la morosidad en el pago.

32 Por ejemplo, la STS de 27 de julio de 1976 (RJ 1976/1928) sostiene que "evidentemente, una de las varias características de la Propiedad Horizontal es la de estar regida por normas de Derecho necesario. Ahora bien, ello no implica que, respecto a dicha clase de Propiedad, no sea de aplicación, en ningún caso, el principio de la autonomía de la voluntad del CC, porque 
notarial, se va imponiendo la inclusión en las escrituras de cláusulas al final de los contratos inmobiliarios o mercantiles, de sometimiento para resolver los conflictos o divergencias que surjan en los juzgados o Tribunales o arbitraje o mediación ${ }^{33}$. El propio art. 2, 2 de la Ley catalana 15/2009, de 22 de julio regula la posibilidad de utilizar la mediación en los conflictos derivados de la propiedad horizontal ${ }^{34} \mathrm{y}$ así lo ha interpretado POSE VIDAL para quien la Ley señala la mediación como una herramienta útil en relación con aquellos conflictos que surgen en el ámbito de las relaciones vecinales que se desarrollan en el contexto de la propiedad horizontal, siendo numerosas las situaciones de enfrentamiento o divergencia por cuestiones cotidianas tales como ruidos, humos y desatención de espacios comunes, situaciones que también se reproducen en las relaciones vecinales en urbanizaciones, provocando situaciones y actitudes en la vida diaria que provocan malestar, tensiones, conflictos de convivencia, en los que la mediación permite soluciones a medida de las necesidades concretas, y que presenta la ventaja de incrementar la eficacia de los acuerdos alcanzados entre las partes ${ }^{35}$.

Al analizar la introducción de las cláusulas de mediación en el ámbito de la Propiedad Horizontal, hay que detenerse en el estudio de dos cuestiones: una, qué materias van a poder ser objeto de mediación y dos, quién o quiénes van a ser los encargados de llevarla a término.

Por lo que se refiere a la primera cuestión, hay que hacer referencia al alcance de la autonomía de la voluntad de los propietarios en este tema.

El poder de disposición de las partes debe existir para que el asunto sea susceptible de conciliación o de mediación (también de arbitraje). En materia de propiedad horizontal debe tenerse en cuenta en primer lugar lo que dispone el art. 396 in fine CC: "Esta forma de propiedad se rige por las disposiciones legales espaciales y, en lo que las mismas permitan, por la voluntad de los interesados". Por tanto, en materia de propiedad horizontal determinados asuntos serán conciliables, mediables o arbi-

según se expresa en la Disposición transitoria de la Ley mencionada, los Estatutos aprobados por la Junta de Propietarios podrán ser aplicados cuando no contradigan lo establecido en la misma. En la Exposición de Motivos de esa Ley especial se admite "que por obra de la voluntad se especifiquen, completen y hasta se modifiquen ciertos derechos y deberes, siempre que no contravengan las normas de Derecho necesario, claramente deducibles de los mismos términos de la Ley".

33 MARTÍNEZ ORTEGA, J.C.: División Horizontal y Obra Nueva: Formalización notarial e inscripción registral, Ed. Dykinson, Madrid, 2015, p. 359.

34 2. La mediación civil a la que se refiere la presente ley comprende cualquier tipo de cuestión o pretensión en materia de derecho privado que pueda conocerse en un proceso judicial y que se caracterice porque se hay a roto la comunicación personal entre las partes, si estas deben mantener relaciones en el futuro y, particularmente, entre otros:

a) Los conflictos relacionales surgidos en el ámbito de las asociaciones y fundaciones.

b) Los conflictos relacionales en el ámbito de la propiedad horizontal y en la organización de la vida ordinaria de las urbanizaciones.

c) Las diferencias graves en el ámbito de la convivencia ciudadana o social, para evitar la iniciación de litigios ante los juzgados.

35 "Comentario al artículo 2..., p. 30. 
trales por darse tal libre poder de disposición ${ }^{36}$. Autonomía de la voluntad reflejada en la LPH cuyo límite en el respeto al derecho necesario, o normas de ius cogens, se pueden encontrar en su Exposición de Motivos y en sus artículos 5 y $6^{37}$. En este sentido se ha pronunciado la sentencia de la Audiencia Provincial de Córdoba de 16 de junio de $1999^{38}$ que apunta a la constante doctrina del Tribunal Supremo en orden a declarar la nulidad de las cláusulas estatutarias que contradigan lo dispuesto en el art. 5 LPH "declarando la nulidad de cláusulas estatutarias que contradigan lo dispuesto en el art. 5 de la citada Ley, puesto que priman sobre el citado principio de autonomía de la voluntad las relaciones de vecindad" y "es evidente que la aplicación del principio se seguridad jurídica y de igualdad se hace imprescindible en supuestos como el presente, a fin de evitar resultados contradictorios en relaciones presididas no por el principio de autonomía de la voluntad sino por el de conservación y mantenimiento de unas normales relaciones de vecindad" para añadir que "tal concepción, por cierto, no sólo es ratificada, sino que se acrecienta con la reciente modificación de la Ley de Propiedad Horizontal por Ley 8/1999, de 6 de abril, puesto que ya desde su Exposición de Motivos se apunta a una sustitución de la clásica concepción de propiedad espacial de la comunidad de propietarios por una concepción de comunidad vecinal de base corporativa, con estructura organizativa democrática reconocida y amparada por la Ley”.

La posibilidad de introducir cláusulas de arbitraje o mediación en el régimen jurídico de la propiedad horizontal a través de los Estatutos de comunidad se ha visto reforzada y justificada por la posición del Tribunal Supremo a este respecto, tal y como se aprecia en su resolución de 27 de septiembre de $2006^{39}$ ya que "la normati-

36 SERRANO HOYO, G.: "Resolución no jurisdiccional de controversias en el ámbito de la propiedad horizontal", en AA,VV, [SAN CRISTOBAL REALES (Coord.)], Estudios sobre propiedad horizontal, Madrid, 2009, p. 1153.

37 PÉREZ MIRALLES, Arbitraje y mediación ..., p. 188.

38 AC 1999/6093.

$39 \quad R J 2006 / 8627$. Criterio mantenido por las SSAAPP de Almería de 25 de octubre de 2007 (JUR 2008/218991) que sostiene que "Los actuaciones que surjan entre propietarios, o entre estos y la Comunidad, se resolverán por medio de arbitraje, de acuerdo con la Ley". Nos encontramos, por tanto, con una disposición que vincula a todos los copropietarios de la Comunidad; "norma" que no está prohibida, por la Ley reguladora de la propiedad horizontal (Ley 49/00 y posteriores reformas), que, antes bien, la contempla expresamente como adecuada forma de resolver los conflictos entre comuneros: (art. 10.3. "En caso de discrepancia sobre la naturaleza de las obras a realizar, resolverá lo procedente la Junta de Propietarios. También podrán los interesados solicitar "arbitraje"; o dictamen técnico en los términos establecidos en la Ley"), Madrid de 28 de Enero de 2008 (LA LEY 5839/2008) y de 26 de Julio de 2011(JUR 2011/438030) que ratifica este criterio al señalar que "Pero de la misma forma que es posible que el titulo constitutivo de la propiedad establezca el arbitraje también lo es que el mismo pueda ser acordado por los comuneros en cualquier Junta, posibilidad igualmente prevista en la Exposición de Motivos de la misma ley cuando permite que "por obra de la voluntad se especifiquen, completen y hasta se modifiquen ciertos derechos y deberes, siempre que no contravengan las normas de Derecho Necesario, claramente deducibles de los mismos términos de la Ley “, y autorizada por lo dispuesto en el art. 396 del C.C. que señala que "esta forma de propiedad se rige por las disposiciones legales especiales $y$, en lo que las mismas permitan, por la voluntad de los interesados" y por el art. 14, c) de la LPH 
va especial que rige el régimen de la propiedad horizontal no se limita a establecer reglas orientadas a regular la utilización de los elementos comunes y el conjunto de derechos y deberes de los propietarios con relación a los mismos, sino que trasciende ese limitado ámbito para alcanzar al complejo conjunto de relaciones que surgen de la coexistencia de elementos privativos y elementos comunes, estableciendo un régimen de derechos y obligaciones, y también por tanto, de responsabilidad que recae no solo sobre los elementos comunes, sino también por los privativos, en lo que constituyen verdaderas limitaciones del derecho de propiedad, justificadas por la necesidad de ordenar y a no la mera coexistencia de intereses económicos, sino un autentica comunidad de vida. Lo que explica por qué los estatutos pueden válidamente contener una cláusula de sumisión a arbitraje... ".

Incluso cabe la posibilidad de una sumisión tácita al arbitraje y la mediación, como es el caso de la sentencia de la Audiencia Provincial de Madrid de 5 de octubre de $2009^{40}$.

En el ámbito de la propiedad horizontal, habrá supuestos que no son susceptibles de conciliación ni de mediación o arbitraje por tratarse de supuestos de Derecho necesario, como por ejemplo la impugnación de acuerdo ${ }^{41}$ o todo lo relacionado con la convocatoria y funcionamiento de las juntas de comunidad de propietarios ${ }^{42}$.

Las materias que por no tener la naturaleza de Derecho necesario pueden ser objeto a modo de ejemplo, podemos $\operatorname{citar}^{43}$ :

- Los conflictos entre los propietarios o entre alguno de ellos y la comunidad por incumplimiento de las obligaciones de adecuado uso y mantenimiento en buen estado de los elementos privativos y comunes impuestas por los artículos 7 y 9 LPH.

— Los conflictos derivados de la reclamación de deudas del art. 21 LPH por incumplimiento de los dueños de su obligación de contribuir al sostenimiento del inmueble y al fondo de reserva.

- Las reclamaciones de los propietarios contra las actuaciones de los órganos de gobierno unipersonales.

— La fijación de la cuota de participación de los diferentes pisos o locales.

que señala con relación a la competencia de las Juntas de Propietarios, que tienen las de "conocer y decidir en los demás asuntos de interés general para la Comunidad, acordando las medidas necesarias o convenientes para el mejor servicio común". Queda por tanto al arbitrio de los comuneros establecer el arbitraje en los estatutos, o aprobarlo en la junta de propietarios, bastando en este último caso para su establecimiento la mayoría simple del art. 17,3 de la LPH (mayoría del total de propietarios que, a su vez, representen la mayoría de las cuotas de participación) pues dicho acuerdo no se puede encuadrar en ninguno de los supuestos configurados como acuerdos especiales".

40 JUR 2010/21284.

$41 \quad$ SAP Alicante de 11 de junio de 2002 (AC 2002/1237).

42 STS de 29 de octubre de 1993 (RJ 1993/ 8165).

43 MORGADO FREIGE, Ma.P: "La resolución de conflictos en el negocio inmobiliario: especial referencia a las controversias en la propiedad horizontal" en Arbitraje: Revista de Arbitraje comercial y de inversiones, vol. XI, nº 2, 2018, pp. 544 y 545. 
- La determinación de la naturaleza de las obras y actuaciones contempladas en los artículos 10 y 17 LPH. En este apartado cabe señala la posibilidad que tienen aquellos propietarios que argumentando incapacidades o ser mayores de setenta años, solicitan a la comunidad la instalación de ascensores u otros mecanismos en aras de hacer efectiva la accesibilidad del inmueble, al amparo de lo dispuesto en al art. 10,1, b) LPH y ésta no accede a sus pretensiones. Para ECHEVERRÍA SUMMERS, "estos propietarios pueden optar por recurrir al sistema arbitral o de mediación para la resolución de quejas y reclamaciones en materia de igualdad de oportunidades, no discriminación y accesibilidad por razón de discapacidad, regulado en el RD 1417/2006, de 1 de diciembre, si bien la norma deja bien claro que el sometimiento de las partes a este sistema arbitral deberá ser voluntario y constar expresamente por escrito" ${ }^{44}$.

- La mediación ante la imposibilidad de lograr un acuerdo por la Junta de propietarios.

- Las reclamaciones de la comunidad frente a terceros.

En cuanto a la competencia para solicitar la mediación, tanto si la comunidad intenta la conciliación como si se solicita respecto a ella, debe resolverse a quien corresponde el poder de disposición de la comunidad que, como sabemos, no tiene personalidad jurídica: el Presidente la representa en juicio y fuera de él, pero la Junta de Propietarios es el órgano de gobierno colegiado que debe conocer y decidir de los "asuntos de interés general para la comunidad acordando las medidas necesarias o convenientes para el mejor servicio común", según el art. 14,e) LPH. Por tanto, salvo que exista un acuerdo previo de la Junta de Propietarios que faculte al Presidente a negociar o, mejor dicho, a disponer de los intereses en juego hasta determinado punto, parece que lo acordado por el órgano de gobierno unipersonal de la comunidad con la otra parte en conflicto (sea propietario o tercero) está sujeto a la aprobación de la Junta de Propietarios. La transacción de la comunidad necesita manifestación de la voluntad de transigir de la misma, no bastando la voluntad de la persona física que actúa por ella en el acto de conciliación judicial, sino la de la Junta de Propietarios a cuya sesión todos habrán sido convocados para que puedan expresar su parecer sobre la transacción ${ }^{45}$.

En lo relativo al perfil del mediador en materia de propiedad horizontal, entiendo que dada la especialidad de la materia sería conveniente que el mediador fuera un profesional conocedor de la materia y en contacto con la realidad y problemática de las comunidades de propietarios, por ejemplo, el administrador de fincas ${ }^{46}$.

Para concluir sólo cabe reseñar la necesidad y eficacia de la mediación como fórmula de resolución de conflictos no jurisdiccional en las relaciones de vecindad y del propio régimen de Propiedad Horizontal.

44 "Comentario al Artículo 10". Comentarios a la Ley de Propiedad Horizontal. BERCOVITZ RODRÍGUEZ-CANO, R. (Coord.). Ed. Aranzadi, Pamplona, 2014, p.385.

45 SERRANO HOYO, G. "Resolución no jurisdiccional de controversias..., p. 1158.

46 A título de ejemplo, cabe citar, el REGLAMENTO DEL CENTRO DE MEDIACIÓN INMOBILIARIA (CEMEI), Colegio de Administradores de Fincas de Valencia (Valencia Caste1lón). 


\section{BIBLIOGRAFÍA}

ADÁN DOMENECH, F: “La mediación en la ejecución hipotecaria”, Rev. Vasca de Derecho Procesal y Arbitraje, 2016 (1).

BASTANTE GRANELL: "Mediación Hipotecaria: Una solución al problema del sobreendeudamiento de los particulares”, ANALES DEL DERECHO, nº 31, 2013.

CORTÉS, J.M. “Arbitraje en materia de arrendamientos". Actualidad Jurídica, Ed. Aranzadi, año XVIII, n ${ }^{\circ}$ 748, 27 de marzo de 2008.

CREMADES B.M.: “El Convenio arbitral”, Diario La Ley no 5754, 4 de abril de 2003, Madrid.

ECHEVERRÍA SUMMERS, FCO.M.: “Comentario al Artículo 10”. Comentarios a la Ley de Propiedad Horizontal. BERCOVITZ RODRÍGUEZ-CANO, R. (Coord.). Ed. Aranzadi, Pamplona, 2014.

FERNÁNDEZ-FIGARES MORALES, Ma.: "La mediación hipotecaria de Andalucía. Examen de la repercusión jurídico-procesal y la habilitación competencial de la Ley 3/2016 que la instaura", Actualidad Civil, n 5, sección consumidores, mayo 2017.

MARTÍNEZ ORTEGA, J.C.: División Horizontal y Obra Nueva: Formalización notarial e inscripción registral, Ed. Dykinson, Madrid, 2015.

MORENO, B.: "El arbitraje arrendaticio con especial referencia al arbitraje del Consejo arbitral para el alquiler de la Comunidad de Madrid" en Arbitraje y mediación en el ámbito arrendaticio, PÉREZ-UGENA, Mª (Coord.), Ed. Dykinson, Madrid, 2017.

MORGADO FREIGE, M․P.: "La resolución de conflictos en el negocio inmobiliario: especial referencia a las controversias en la propiedad horizontal" en Arbitraje: Revista de Arbitraje comercial y de inversiones, vol. XI, nº 2, 2018.

ORTUÑO MUÑOZ, P.:“A propósito del ámbito de la directiva 2008/52/ce, sobre medición, en asuntos civiles y mercantiles". Rev. Doctrinal Aranzadi Civil-Mercantil, $n^{\circ}$ 20/2008, Ed. Aranzadi, Cizur Menor, 2008.

PÉREZ DAUDÍ: “Aspectos procesales de la mediación preceptiva en los procesos hipotecarios". Diario LA LEY, n 8541, Sección Tribuna, 18 de mayo de 2015.

PÉREZ MIRALLES, J.A.: Arbitraje y mediación inmobiliaria. Especial referencia a la propiedad horizontal, Ed. Tirant lo Blanch, Valencia, 2012.

POSE VIDAL, S. “Comentario al artículo 2" en Comentarios a la Ley catalana 15/2009, de 22 de julio, de mediación en el ámbito del Derecho privado y concordantes, VIOLA DEMESTRE, I. (Dir.), Ed. Marcial Pons, Madrid, 2018.

REY BARBA, S: “¿Es posible el arbitraje hipotecario?, RCDI, nº 758, 2016.

ROGEL VIDÉ, C.: "Mediación y transacción en el Derecho Civil" en Mediación, arbitraje y resolución extrajudicial en el siglo XXI, GARCÍA VILLALUENGA, L., TOMILLÓN URBINA, J. L. y VÁZQUEZ DE CASTRO, E. (Codirectores), Ed. REUS, Madrid, 2010.

SERRANO HOYO, G.: "Resolución no jurisdiccional de controversias en el ámbito de la propiedad horizontal", en AAVV, [SAN CRISTOBAL REALES (Coord.)], Estudios sobre propiedad horizontal, Madrid, 2009. 